\title{
Food effects on life history traits and seasonal dynamics of Ceriodaphnia pulchella
}

\author{
MAARTEN BOERSMA* AND JACOBUS VIJVERBERG \\ Netherlands Institute of Ecology, Centre for Limnology, Rijksstraatweg 6, 3631 AC Nieuwersluis, the Netherlands \\ *Present address: Max-Planck-Institut für Limnologie, Postfach 165, D-24302 Plön, Germany
}

\section{S U M M A R Y}

1. This paper describes the effects of differences in food quantity and quality on selected life history traits of Ceriodaphnia pulchella. Animals were fed with four concentrations of two green algae, Scenedesmus obliquus and Chlamydomonas globosa, given separately as well as in a $1: 1$ mixture.

2. In most cases growth, reproduction and condition of the animals and consequently the rate of population increase, $r$, increased with food concentration. Life history parameters of animals raised on S. obliquus were lowest, whereas no significant differences were found between animals fed with C. globosa and with the mixture of the two algal species.

3. In contrast to the large effects of food quantity and quality found in the laboratory, an analysis of the population dynamics of $C$. pulchella in Lake Tjeukemeer showed that the effect of changes in food conditions during the growing season of this species was limited, although overall food levels seemed to be poor throughout the year.

4. Changes in the birth rate of the population are mainly governed by changes in temperature, and possibly by changes in the densities of the invertebrate predator Leptodora kindtii.

\section{Introduction}

Aquatic filter feeders are among the most non-selective consumers, often ingesting all particles within a given size range, including algae, bacteria, protozoa and detritus. This implies that these animals are faced with a large spectrum of resources of varying quality. Since the ability for food selection seems limited, differences in both food quantity and quality are likely to be of importance to these animals. While the effect of food quantity on life history characteristics of zooplankton has been addressed by many workers (e.g. Lampert, 1977; Duncan, Lampert \& Rocha, 1985), influences of food quality have received considerably less attention. Only relatively recently have differences in quality among (e.g. Ahlgren et al., 1990; Lundstedt \& Brett, 1991) and within food species as a result of the culturing conditions of the algae (Müller-Navarra, 1993; Sterner, Hagemeier \& Smith, 1993; van Donk \& Hessen, 1993) become the subject of research.
Even though roughly half the studies reviewed by Vijverberg (1989) on growth and reproduction in zooplankton were carried out with a combination of food types, only a few papers deal with the effects of different food types fed to herbivorous zooplankton both in combination and alone (Jamieson, 1980; Lewis \& Maki, 1981; Hanazato \& Yasuno, 1984; Roman, 1984; Cowgill, Keating \& Takahashi, 1985; Lundstedt \& Brett, 1991; Vanni \& Lampert, 1992; Boersma \& Vijverberg, 1995). Although poorly studied in zooplankton the phenomenon of complementary resources seems to be important in a wide variety of consumers (see references in Pennings, Nadeau \& Paul, 1993), with two or more food sources each providing different proportions of different essential elements (Tilman, 1982).

In this paper we present a study of the effects of feeding Ceriodaphnia pulchella Sars with different 
concentrations of two green algae, Scenedesmus obliquus (Turp.) Kürtz. and Chlamydomonas globosa Snow, on selected life history traits. Both algal species have been used extensively as food for zooplankton, and are considered to be high quality food sources (Vijverberg, 1989).

As many zooplankton species appear to be food limited during large parts of the year (Tessier, 1986; Chapman \& Burns, 1994; Manca, Spagnuolo \& Comoli, 1994; Boersma \& Vijverberg, 1994c) the effect of food on the seasonal dynamics of herbivorous zooplankton species has been a well-researched field. Most studies, however, have focused on Daphnia species, and only a small number of studies has appeared on the seasonal dynamics of smaller cladocerans (e.g. DeMott \& Kerfoot, 1982; Balseiro, Modenutti \& Queimalinos, 1992). Therefore, we assessed the importance of changing food conditions in the determination of the population dynamics of the smaller crustacean, Ceriodaphnia pulchella. As direct assessments of food level and food quality under field conditions are difficult, the analysis of the effect of food conditions was done indirectly. Carbon content and fecundity of the animals in the field were monitored, and the effects of different environmental factors on the birth rate were analysed.

\section{Materials and methods}

\section{Laboratory}

Chlamydomonas globosa and Scenedesmus obliquus were cultured axenically in 2-1 flow-through systems (Boersma \& Vijverberg, 1994b). The algae were harvested daily from the overflow bottles of these continuous cultures. The culture medium of the algae was removed by centrifuging twice for $20 \mathrm{~min}$ at 3000 r.p.m., and by subsequent washing of the algae with distilled water. The algae were resuspended in 0.45$\mu \mathrm{m}$-filtered Lake Tjeukemeer water. The algal density was measured using a haemacytometer, counting a minimum of 500 cells. The carbon content of C. globosa was $2.52 \times 10^{-11} \mathrm{~g} \mathrm{C}$ cell $^{-1}$, and that of $S$. obliquus was $2.30 \times 10^{-11} \mathrm{~g} \mathrm{C} \mathrm{cell}^{-1}$, resulting in carbon : dry weight ratios of 0.53 and 0.50 , respectively. Scenedesmus obliquus was usually unicellular. Both algal species had a maximum length of around $15 \mu \mathrm{m}$.

Ceriodaphnia pulchella individuals were collected with a $120-\mu \mathrm{m}$ tow net from Lake Tjeukemeer. The animals were placed individually in 100-ml test tubes and fed on a $1: 1$ mixture of C. globosa and S. obliquus. The algal carbon content of this culture medium was $1 \mathrm{mg} \mathrm{Cl}^{-1}$. The incubation temperature used was $17.5^{\circ} \mathrm{C}$, and the light: dark regime was $16: 8 \mathrm{~h}$. As soon as the field-caught animals produced newborn the mothers were removed. The first generation animals were reared to maturity on the same medium as their mothers. The offspring produced by these animals were used for the experiments described below.

Different amounts of C. globosa and S. obliquus were added to $0.45-\mu \mathrm{m}$-filtered Tjeukemeer water to obtain four food levels, with carbon contents of 0.13, 0.25, 0.50 and $2.5 \mathrm{mgCl}^{-1}$, respectively. Three types of media were prepared: (i) a series of pure C. globosa media (CHLAM); (ii) a series of $S$. obliquus media (SCENE); and (iii) a series of C. globosa and S. obliquus in a 1:1 mixture (CH_SC). The temperature and photoperiod used in the experiments were the same as during the acclimatization period. For each series, forty neonates were collected within $12 \mathrm{~h}$ of birth, and placed individually in 100-ml test tubes. The animals were selected in such a way that the clonal composition of all series was the same. The animals were examined daily for moulting by inspection of the medium for exuviae, and transferred to clean tubes with fresh medium. The time needed to reach maturity, defined as the first appearance of eggs in the brood pouch, the size at maturity, and the number of juvenile instars of the animals were recorded. Once the animals reached maturity, the number of eggs was counted for each adult instar. Growth and reproduction were measured until the animals reached the fourth adult instar. The rate of increase $(r)$ was estimated using the Euler equation, and standard errors for $r$ were computed using a jackknifing method (Meyer et al., 1986). As only one value of $r$ was available per treatment it was impossible to compute the significance of the interaction between food type and the food concentration. In order to overcome this problem we split the animals per treatment randomly, and computed $r$ for each of these two series per treatment, yielding two independent estimates of $r$.

\section{Field}

In 1991 quantitative zooplankton samples were taken weekly with a 5-1 Friedinger volume sampler at five stations in Lake Tjeukemeer, a shallow, eutrophic, 
polymictic lake in the northern part of the Netherlands (mean depth $1.5 \mathrm{~m}$, surface area $21 \mathrm{~km}^{2}$ ). Sampling was done at two depths, one below the surface and the other just above the bottom. These samples were pooled, concentrated by filtration through a $120-\mu \mathrm{m}$ filter and preserved in a $4 \%$ formaldehyde solution. Total number of animals and length-frequency distributions were measured in a one-tenth subsample. Preserving animals in formaldehyde may cause egg loss from the brood chamber, hence an additional sample was taken and preserved in 95\% ethanol. Length-fecundity relations were established using this sample.

A formal way to test influences of different factors on changes in the birth rate was proposed by Polishchuk (1994; 1995). The well-known formula of Paloheimo (1974):

$$
b=\ln (1+E) / D
$$

where $b$ is the birth rate, $D$ is the egg development time, and $E$ is the average number of eggs in the population, is rewritten to yield the following equation:

$$
b=V \ln (1+F A)
$$

where $V=1 / D, F$ is the fecundity (mean number of eggs per adult female) and $A$ is the proportion of adults in the population. Polishchuk $(1994 ; 1995)$ then computed the contribution (Con) of the different factors to changes in the birth rate using partial derivatives, resulting in the following expressions for these contributions:

$$
\begin{aligned}
& \text { Con } V=\ln (1+F A)(\mathrm{d} V / \mathrm{d} T) \\
& \text { Con } F=V A /(1+F A)(\mathrm{d} F / \mathrm{d} T) \\
& \text { Con } A=V F /(1+F A)(\mathrm{d} A / \mathrm{d} T)
\end{aligned}
$$

Polishchuk claimed that the causes behind changes in parameters $V, F$ and $A$ are more directly related to specific environmental conditions than are changes in the birth rate. $V$, the reciprocal of the egg development time, is almost uniquely influenced by the ambient temperatures. $F$, the fecundity, is mainly dependent on food conditions, but may also depend on the age structure of the population, while $A$, the proportion of adults, and hence the age structure of the population, is mostly linked to predation. Polishchuk proposed this method to detect quick changes in the impact of different steering factors on the birth rate of a population and hence on its dynamics.

\section{Carbon content}

Both cultured animals and individuals taken from the field at weekly intervals were washed in distilled water and analysed for carbon while alive (Boersma \& Vijverberg, 1994a). Regression lines were computed with the log-transformed values of length $(\mathrm{mm})$ as the independent variable and the log-transformed carbon content $(\mu \mathrm{g})$ of the animals as the dependent variable.

\section{Results \\ Laboratory}

An effect of both food concentration and food type on the development, growth and reproduction of $C$. pulchella was found (Table 1). Higher food concentrations resulted in a shorter time to reach maturity (Fig. 1a). Size at maturity was only affected by food source and not by the concentration (Fig. 1b). Animals fed solely Scenedesmus were significantly smaller at maturity than the animals reared on the other two media (Table 2), and took longer to mature (Figs 1a and $b$ ). The number of eggs produced by the first adult instar increased with increasing food levels for the mixed food, decreased at the highest food level when the animals were fed with only Chlamydomonas, and was relatively constant for Scenedesmus-fed animals (Fig. 1c). This resulted in a significant food type, concentration and interaction effect (Table 1). Animals fed Scenedesmus produced significantly fewer eggs than the animals reared on the other two media (Table 2; Fig. 1c). Table 1 shows the results of two analyses of variance with $r$. The single measurements of $r$ were analysed first, with the effects of the treatments tested using the interaction term as the error term. Only food type showed a significant effect on $r$. The analysis of split $r$ values showed the existence of a marginally significant interaction, making the analysis of the single $r$ values less interpretable. This split $r$ analysis shows that the effect of food concentration is also significant (Table 1). Animals reared on the SCENE series showed the lowest values for $r$ in all cases (Fig. 1d). As was the case with the single life history traits, the overall differences between the three food types were significant between the SCENE and the two other series only (Table 2).

Regression lines of the log-transformed values of length with the log-transformed carbon contents 

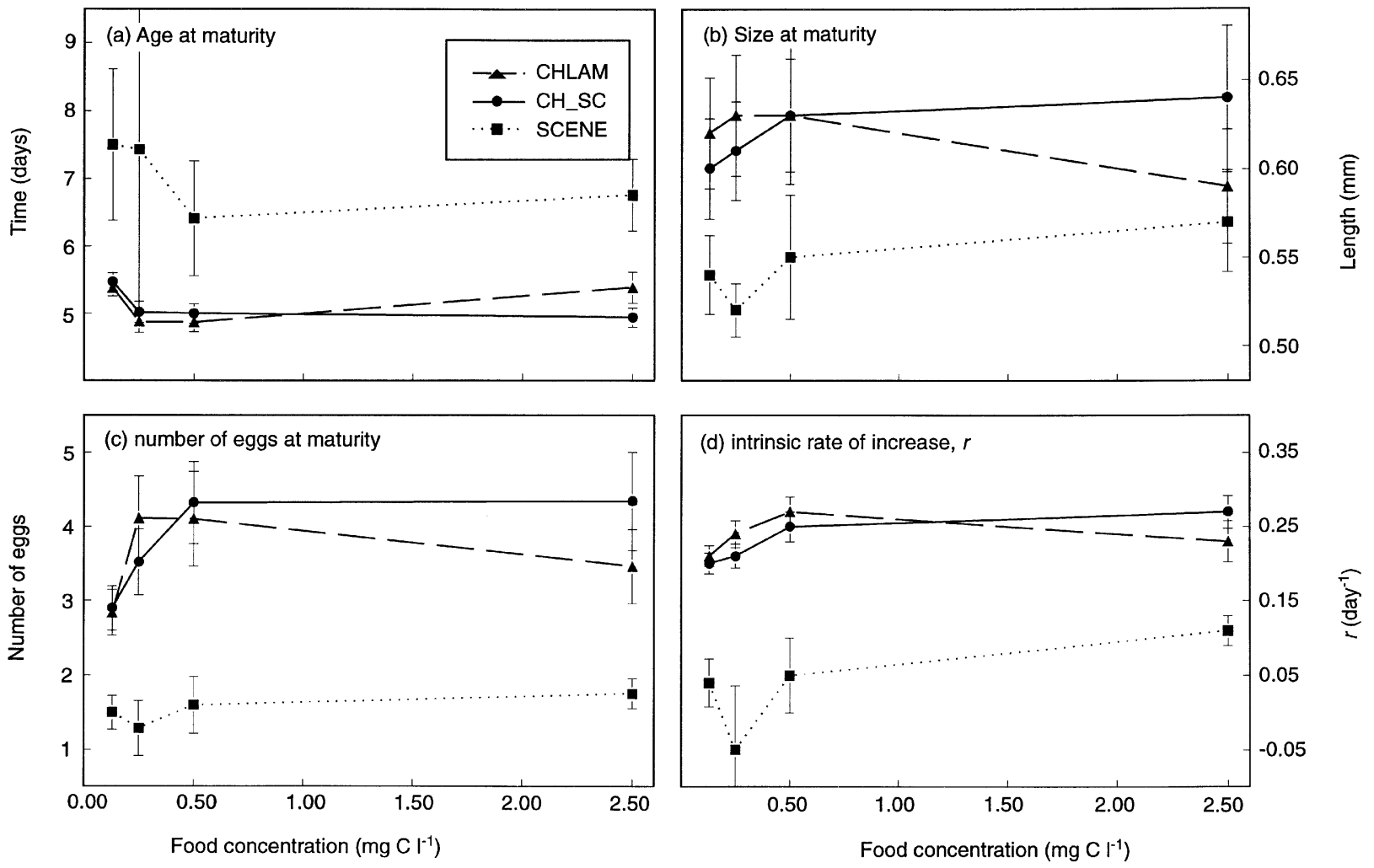

Fig. 1 The response of selected life history traits of Ceriodaphnia pulchella to the different experimental treatments. The food types used were Chlamydomonas globosa (CHLAM, dashed line, triangles), a 1:1 mixture of C. globosa and Scenedesmus obliquus (CH_SC, solid line, circles), and S. obliquus (SCENE, dotted line, squares). Error bars indicate $95 \%$ confidence limits of the means in all cases. (a) Time needed for neonates to reach maturity; (b) size at maturity (mm); (c) mean number of eggs per primiparous female; (d) rate of population increase, $r\left(\right.$ day $\left.^{-1}\right)$.

Table $1 \mathrm{~F}$ values of two-way ANOVAs for selected life history characteristics of Ceriodaphnia pulchella. The numbers of eggs per female were square-root transformed and carbon contents were log-transformed

\begin{tabular}{|c|c|c|c|c|c|c|c|c|c|c|}
\hline \multirow[b]{2}{*}{ Trait } & \multirow[b]{2}{*}{ Error df } & \multicolumn{3}{|c|}{ Food type } & \multicolumn{3}{|c|}{ Food concentration } & \multicolumn{3}{|c|}{ Interaction } \\
\hline & & d.f. & $F$ & $P$ & d.f. & $F$ & $P$ & d.f. & $F$ & $P$ \\
\hline Time to maturity & 326 & 2 & 75.6 & $<0.001$ & 3 & 5.7 & $<0.001$ & 6 & 1.6 & 0.160 \\
\hline Size at maturity & 325 & 2 & 17.6 & $<0.001$ & 3 & 0.7 & 0.567 & 6 & 1.6 & 0.145 \\
\hline Egg number & 295 & 2 & 83.8 & $<0.001$ & 3 & 6.7 & $<0.001$ & 6 & 2.4 & 0.028 \\
\hline$r$ & 6 & 2 & 36.9 & $<0.001$ & 3 & 2.3 & 0.177 & - & - & - \\
\hline Split $r$ & 12 & 2 & 143.3 & $<0.001$ & 3 & 6.0 & 0.010 & 6 & 2.5 & 0.086 \\
\hline Carbon content & 267 & 2 & 17.5 & $<0.001$ & 3 & 1.7 & 0.160 & 6 & 1.6 & 0.143 \\
\hline
\end{tabular}

differed significantly in slope between the different experimental treatments $\left(F_{11,256}=3.05 ; P<0.001\right)$. This was mainly caused by the regression lines of the animals reared on two of the SCENE media ( 0.25 and $\left.0.50 \mathrm{mg} \mathrm{C}^{-1}\right)$, although only four and five animals were analysed, respectively, as a result of poor growth. After deletion of these two series the regression coeffi- cients were no longer significantly different, which allowed a length-independent estimation of the carbon content of the animals. Using the common slope and the different intercepts of the length-carbon regressions at the different food types and concentrations, the logarithm of the carbon content of $0.6 \mathrm{~mm}$ individuals, which is the long-term average size of adult C. pulchella 
Table 2 Probabilities of Tukey HSD tests between the different food media for selected life history characteristics of Ceriodaphnia pulchella. The significance of the differences between different combinations of the three food media (CHLAM, pure Chlamydomonas globosa; SCENE, pure Scenedesmus obliquus; CH_SC, $1: 1$ mixture of $C$. globosa and S. obliquus) is shown

\begin{tabular}{llll}
\hline Trait & CH_SC- & CH_SC- & SCENE- \\
& CHLAM & SCENE & CHLAM \\
\hline Time to maturity & 0.981 & $<0.001$ & $<0.001$ \\
Size at maturity & 0.967 & $<0.001$ & $<0.001$ \\
Egg number & 0.576 & $<0.001$ & $<0.001$ \\
$r$ & - & - & - \\
Split $r$ & 0.846 & $<0.001$ & $<0.001$ \\
Carbon content & 0.427 & $<0.001$ & $<0.001$ \\
\hline
\end{tabular}

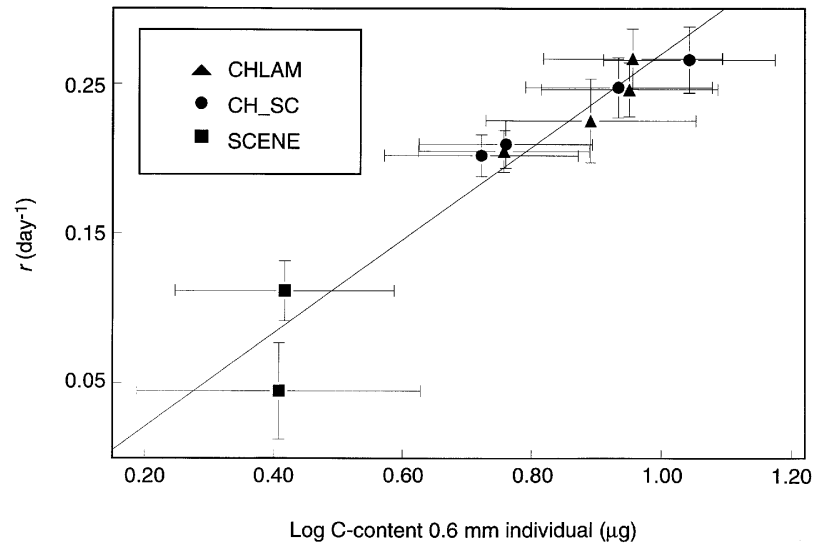

Fig. 2 Relation between the natural logarithm of the carbon content of hypothetical $0.6 \mathrm{~mm}$ individuals as calculated from the length-carbon regressions $(\mu \mathrm{g})$ and $r\left(\mathrm{day}^{-1}\right)$. The correlation was significantly larger than zero $(r=0.96$; $P<0.001 ; n=10)$.

in Lake Tjeukemeer, was computed. These values correlated significantly with the computed values of $r$ for the different series $(r=0.96 ; P<0.001$; $n=10$ ) (Fig. 2).

\section{Field}

Fig. 3 shows the population dynamics of C. pulchella in 1991, and the values of the rate of population increase, $r$. C. pulchella was present only in the summer months, between June and the end of October. The seasonal changes in birth and death rates are shown in Fig. 4. A correlation coefficient significantly different from zero was found between $r$ and $b(0.47 ; P=0.036$; $n=20)$.

(C) 1996 Blackwell Science Ltd, Freshwater Biology, 35, 25-34

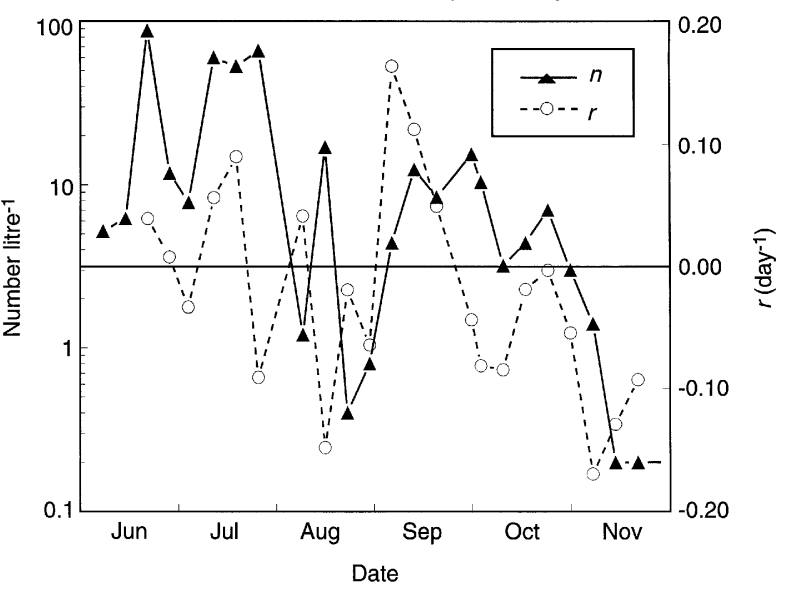

Fig. 3 Seasonal dynamics of Ceriodaphnia pulchella in the year 1991 , numbers $~^{-1}(n)$ and rate of population increase, $r$ (day ${ }^{-1}$, smoothed using a three point running average).

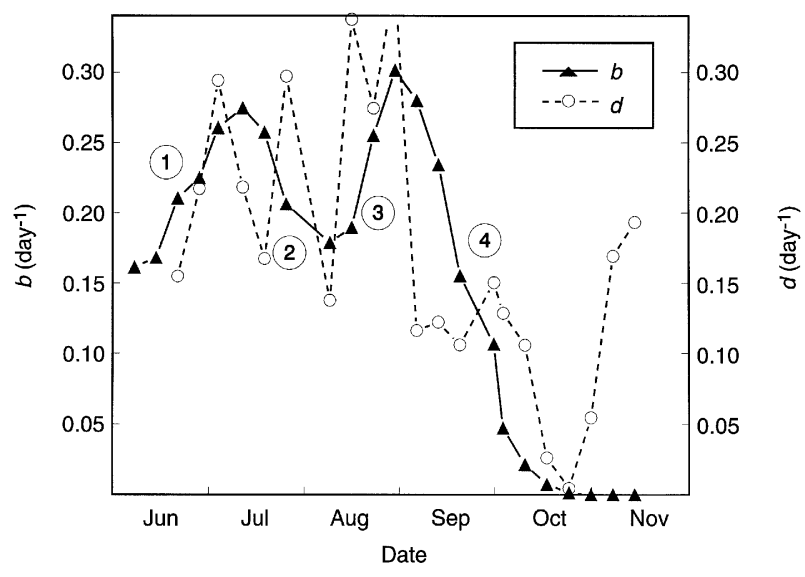

Fig. 4 Seasonal changes in birth and death rates of Ceriodaphnia pulchella $\left(\right.$ day $\left.^{-1}\right)$. Both rates were smoothed using a three point running average. The numbers indicate the different periods of monotonously increasing or decreasing birth rates (see text).

Length-carbon regression lines for animals collected in the field were not significantly different in slope between the different sampling dates $\left(F_{13,353}=0.96\right.$; $P=0.491)$ and, hence, an analysis of covariance was applied to compare the intercepts of the different sampling dates, which proved to be significantly different $\left(F_{13,366}=18.8 ; P<0.001\right)$. Fig. 5 shows the exponential of the computed carbon content for $0.6 \mathrm{~mm}$ individuals. The length-specific carbon content is reported to be a measurement of the condition of the animals, as is the average number of eggs per adult female in a population. This latter quantity, however, showed very little variation during the period of parthenogenetic reproduction (Fig. 5). 


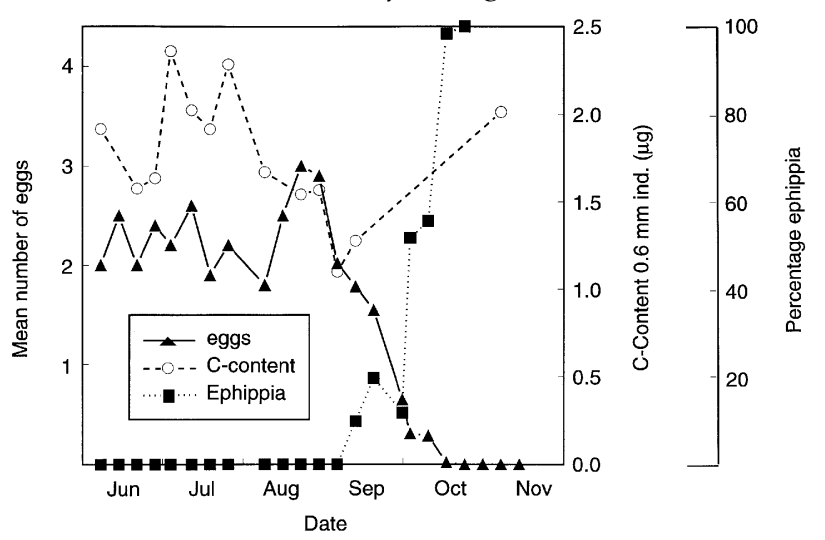

Fig. 5 Seasonal changes in the average number of eggs per adult female, the carbon content of $0.6 \mathrm{~mm}$ individuals $(\mu \mathrm{g})$, and the percentage of reproductively active adult females carrying ephippial eggs.

Hence, these quantities were not correlated $(-0.14 ; P=$ $0.658 ; n=13)$. The values of $r$ and length-specific carbon content were found to be significantly, but negatively correlated $(-0.63 ; P=0.026 ; n=12)$.

Our observation that $r$ is correlated positively with the average number of eggs per adult female (0.49; $P=0.026 ; n=20$ ) suggests that the feeding conditions of C. pulchella are of importance in the population dynamics of this species. Analysing the data using the more formal approach of Polishchuk (1994; 1995) yielded rather scattered results: the relative contribution of the different parameters changed rapidly. It is, however, difficult to imagine that when birth rates change monotonously over a longer period, different factors are causing this behaviour on adjacent sampling dates. Therefore, the data were smoothed with a three-point running average, and the analysis was repeated. In the seasonal pattern of the smoothed birth rates, four periods (Fig. 4) can be recognized, each being characterized by a monotonous increase or decrease in birth rate. The contributions of the three different factors ( $V$, the reciprocal of the egg development time; $F$, the mean number of eggs per adult female; $A$, the proportion of adults) for these four periods were averaged per period, and expressed as a percentage of the total change in birth rate computed (Table 3). The different factors made different contributions to the birth rate in the four periods. In the first period, the steady increase in the birth rate could be attributed almost entirely to changes in egg development time resulting from an increase in the temperature of the lake. The second period was characterized by a decrease in the proportion of adults in the population. This, accompanied by decreasing densities of animals in this period, points to a higher mortality for adults compared with the mortality rate of juveniles. In the third period the percentage adults increased again, causing an increase in the birth rates, suggesting that the higher mortality rates for the adults were relaxed, and the mean age of individuals in the population was increasing. In the fourth period decreasing fecundities and to a lesser extent increasing egg development times could be held responsible for the decrease in birth rates. The sharp decrease in the average number of eggs per adult female in this period suggests that food conditions deteriorated for C. pulchella, but was in fact mainly caused by a drastic increase of the proportion of the females carrying ephippial eggs, rather than by a decline in the number of eggs carried by parthenogenetic females (Fig. 5).

\section{Discussion}

Our laboratory results show that both growth and reproduction in Ceriodaphnia pulchella were influenced by the quantity and the quality of available food, with lower rates on the pure Scenedesmus obliquus media than on the pure Chlamydomonas globosa media, whereas mixed food treatments were never significantly different from the C. globosa treatments. Concentration effects were relatively small, which was caused by the very small differences in growth and reproduction of the animals cultured on the Scenedesmus media (Figs 1a-d), combined with the lower values in the life history parameters of animals cultured on the highest Chlamydomonas level. These results suggest that the incipient limiting level for C. pulchella is below $0.5 \mathrm{mg} \mathrm{Cl}^{-1}$ (see also Lynch, 1992).

Both Chlamydomonas spp. and Scenedesmus spp. are widely used as food for cladocerans and are usually regarded as high quality food items (e.g. Lampert, 1977; Vijverberg, 1989; Ahlgren et al., 1990), although both Chlamydomonas and Scenedesmus species have been reported to be inadequate food for zooplankton (Taub \& Dollar, 1968; Hart \& Santer, 1994; Boersma \& Vijverberg, 1994b). It has become increasingly clear, however, that not only the algal taxonomical status determines food quality for zooplankton, but that also the culture conditions of the algae (Sterner et al., 1993), or the fact that they have come into contact with zooplankton (van Donk \& Hessen, 1993; Lampert, 
Table 3 Average changes of the birth rate, and contributions to these changes of changes in egg development time (Con $V$ ), average number of eggs (Con $F$ ), and the proportion of adults in the population (Con $A$ ), plus the magnitudes of the three relative to the total change in birth rates

\begin{tabular}{lrrrrrr}
\hline Period & $\mathrm{d} b / \mathrm{d} t$ & Con $V$ & Con $F$ & Con $A$ & $\% V$ & $\%=$ \\
\hline Period 1 & 0.0034 & 0.0027 & 0.0001 & 0.0009 & 81 & 2 \\
Period 2 & -0.0039 & 0.0003 & -0.0007 & -0.0034 & -9 & 17 \\
Period 3 & 0.0036 & -0.0007 & 0.0022 & 0.0028 & -20 & -1 \\
Period 4 & -0.0054 & -0.0011 & -0.0040 & -0.0005 & 21 & 74 \\
\hline
\end{tabular}

Rothhaupt \& von Elert, 1994), are of importance for the quality as food for grazers.

This study indicates that under the culture conditions used in our experiments Scenedesmus obliquus is an inadequate food source for C. pulchella. This in contrast to our findings with Daphnia galeata Sars, which showed better growth on Scenedesmus than on Chlamydomonas (Boersma \& Vijverberg, 1995). However, the quality of algae as food may change, even in continuous, axenic, cultures, as we showed in a previous paper (Boersma \& Vijverberg, 1994b) where we observed that the quality of $S$. obliquus changed in such a way that it actually became toxic for daphnids, even though the culture conditions apparently did not change. For C. pulchella the combination of Scenedesmus with Chlamydomonas yielded growth and reproduction rates similar to the pure Chlamydomonas series indicating that, whatever the nutritional inadequacies of Scenedesmus, these were substituted completely by Chlamydomonas cells. This is in contrast to our results with $D$. galeata where we observed that the mixture of the food sources yielded higher growth and reproduction as compared to both mono-algal diets, and hence for $D$. galeata the two algal species seemed to be complementary resources (Boersma \& Vijverberg, 1995).

The method proposed by Polishchuk $(1994 ; 1995)$ is meant to detect rapid changes in important factors changing the birth rate. However, computing the importance of each factor per sampling date yielded results which were difficult to interpret, because the contribution of the different factors to the changes in birth rate varied greatly. Averaging the data over a period with similar qualitative changes in $b$, e.g. periods with increasing or decreasing $b$ values, yielded more interpretable results. We conclude that, although C. pulchella is considered to be a typical summer species of temperate lakes and normally occurs in the months June-October only, temperature usually plays a key role in the determination of birth rate.

(C) 1996 Blackwell Science Ltd, Freshwater Biology, 35, 25-34

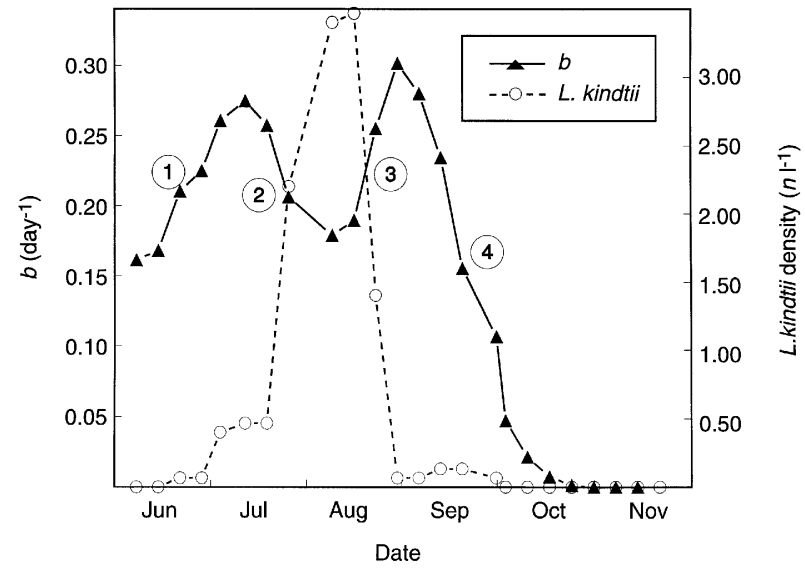

Fig. 6 Birth rates of Ceriodaphnia pulchella $\left(\right.$ day $\left.^{-1}\right)$ and densities of Leptodora kindtii during 1991 (no. $1^{-1}$ ).

In the period July-August, when changes in temperature were of lesser importance, changes in birth rates were mainly governed by changes in the proportion of adults in the population. A decrease of the proportion of adults in the population is usually explained by selective predation on the larger individuals by fish (e.g. Polishchuk, 1994). However, in this case it is difficult to attribute the disappearance of the adults to fish predation, because $0+$ smelt (Osmerus eperlanus Linnaeus), the main planktivorous fish in Lake Tjeukemeer, prefers prey larger than $1.0 \mathrm{~mm}$ at this time of the year. The greatest preference for prey in the range of $0.5-1.0 \mathrm{~mm}$ is usually found in smaller fish and, hence, earlier in the season (Boersma, van Tongeren \& Mooij, 1995). The invertebrate predator Leptodora kindtii Focke, however, showed its peak densities in the periods 2 and 3 (Fig. 6). In populations of Daphnia invertebrate predators, such as L. kindtii, are known to select the smaller animals (Lane, 1978; but see Lunte \& Luecke, 1991). Ceriodaphnia pulchella, however, is much smaller than most Daphnia species, with sizes at maturity in the field around $0.5 \mathrm{~mm}$. In prey selection experiments with L. kindtii as a predator and Diaphanosoma brachyurum Lieven as prey, Herzig \& Auer (1990) 


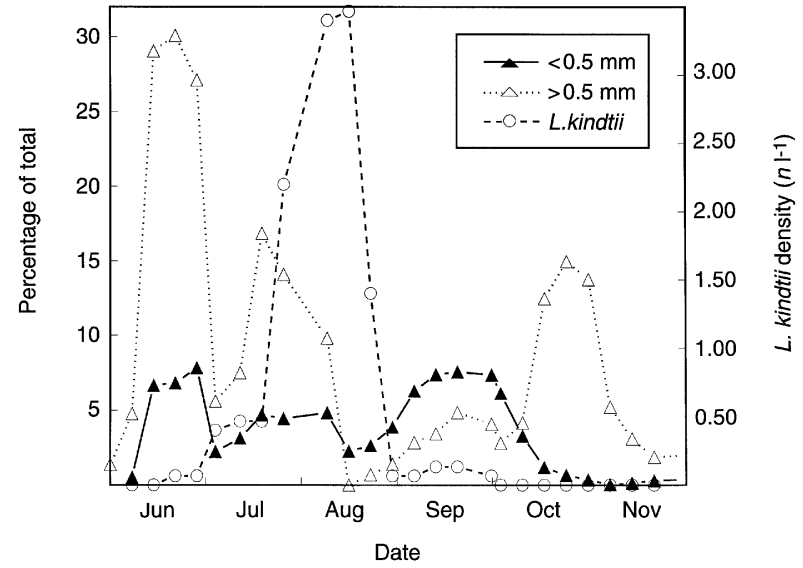

Fig. 7 Densities of Leptodora kindtii (no. $\mathrm{l}^{-1}$ ) and the percentage of the two size classes of Ceriodaphnia pulchella $(<0.5 \mathrm{~mm}$ and $0.5-1.0 \mathrm{~mm}$ ) each in relation to the total densities of cladoceran zooplankton in these size classes.

found that the main sizes of the prey items attacked were between 0.5 and $0.9 \mathrm{~mm}$ and, from their results, it can be concluded that L. kindtii, with lengths of 4$11 \mathrm{~mm}$, hardly forages on prey smaller than $0.5 \mathrm{~mm}$. Hence, in the case of C. pulchella, Leptodora is expected to show positive size-selective predation. This could explain the decreasing proportion of adult Ceriodaphnia with increasing densities of L. kindtii. Others, however, have claimed that $L$. kindtii also consumes large numbers of small cladocerans, such as bosminids and chydorids (e.g. Mordukhai-Boltovskaia, 1958; Lunte \& Luecke, 1991). Browman, Kruse \& O’Brien (1989) concluded that predation by Leptodora is passive, determined mainly by the vulnerability of the prey, as encounter rates are most likely similar. This implies that, assuming also that the prey vulnerability of equally sized cladocerans is similar (Branstrator, 1994), consumption of Leptodora kindtii will be determined strictly by the proportions of the different prey items in the field. Fig. 7 shows the percentages of two size classes of C. pulchella $(<0.5 \mathrm{~mm},>0.5 \mathrm{~mm})$ each in relation to the total densities of cladoceran zooplankton of these size classes. From this graph it can be concluded that in the period of increasing densities of L. kindtii in Lake Tjeukemeer in 1991, the proportion of larger Ceriodaphnia relative to the total density of cladocerans of that size class was higher than the proportion of smaller Ceriodaphnia individuals. This means that, if prey choice is strictly determined by the relative densities of prey items in the field, the larger (adult) individuals of C. pulchella were more vulnerable to predation in this period, and hence the proportion of adults in the population of Ceriodaphnia decreased. This decrease in the proportion of adults caused the observed decline in the birth rate. After the densities of L. kindtii decreased, predation rates on adult C. pulchella decreased, and hence the proportion of adults in the population could rise.

It is possible to estimate the death rates of C. pulchella as a result of predation by L. kindtii. When we assume that: (i) L. kindtii consumes 10 prey ind. day ${ }^{-1}$ (Browman et al., 1989); (ii) this is independent of the prey densities, and hence the prey abundance is always in the saturated range of the predator's functional response (Herzig \& Auer, 1990); (iii) only prey between 0.5 and $1.0 \mathrm{~mm}$ are eaten (Herzig \& Auer, 1990); and (iv) no prey selection takes place, i.e. prey choice is determined solely by the relative densities in the field (Browman et al., 1989), then the death rates for C. pulchella in the period of maximum L. kindtii abundance were around 0.3 day $^{-1}$, values in the same order of magnitude as the values computed for the animals in the field (Fig. 4). No correlation, however, was found between the Leptodora densities and the death rates of $C$. pulchella. This is most likely caused by the effect of sampling errors in $b$ and $r$, accumulating in the estimates of the death rates (see also DeMott, 1980). The analysis of the more accurately estimated birth rates, however, shows that L. kindtii, although scarce, seems capable of affecting population dynamics of its prey species.

The length-corrected carbon contents of the animals in the field in 1991 were correlated negatively with $r$ and not correlated with the average number of eggs in the population. A negative correlation between $r$ and the condition of the animals in the field can be found if the population dynamics of the species are not governed by food conditions which, from the analysis of the changes in the birth rates, seemed to be the case. A non-significant correlation between egg number and carbon content of the animals is more difficult to explain, because most studies report a positive correlation between these two (Duncan et al., 1985; Boersma \& Vijverberg, 1994c; Manca et al., 1994), and our laboratory results also showed a positive correlation between the length-specific carbon content and the average number of eggs. This lack of a significant correlation is probably caused by the relatively low number of observations, by the relatively constant egg numbers of C. pulchella adults early in 
the growing season, and by the increasing proportion of females producing resting eggs later in the season.

It is important to note that, although changes in food quality or quantity do not seem to contribute very much to changes in the birth rate in the field, food conditions for C. pulchella are suboptimal through the whole growing season. This can be concluded from the comparison of the average number of eggs in the field with the average number of eggs produced by primiparous females in the laboratory, and from the higher carbon content of the hypothetical $0.6 \mathrm{~mm}$ animals in the laboratory at the higher food levels as compared with the carbon content of the animals in the field (Figs 2 and 5).

In conclusion, the population dynamics of C. pulchella in Lake Tjeukemeer seem to be governed mainly by temperature and by the positive size-selective predation by the invertebrate predator L. kindtii (see also Branstrator \& Lehman, 1991). Although the condition of the animals changed during the season (Fig. 5), and food has a large impact on the animals under laboratory conditions, changes in food quantity or quality do not seem to play an important role in the seasonal dynamics of $C$. pulchella, even if the animals are food limited. This is in contrast to our findings with Daphnia species in the same lake (Boersma \& Vijverberg, 1994c), which showed distinct periods where food limitation was important. Later in the year the change in fecundity of C. pulchella does have an impact on birth rates. This, however, is a result of the large proportion of animals producing resting eggs in this period, which is probably caused by physical factors, such as a decrease in day length or temperature. The findings reported in this paper indicate that the seasonal dynamics of species which are often lumped into one trophic group, i.e. herbivorous zooplankton, can be driven by different factors.

\section{Acknowledgments}

This study was supported by the Life Science Foundation (SLW), which is subsidized by the Netherlands Organization for Scientific Research (NWO). We thank Aafje Landman, Peter Mac Gillavry and Theo Frank for their assistance in the laboratory. Piet Spaak, Wolf Mooij, Klaus Schwenk, Sari Repka and Bill DeMott are acknowledged for their comments on the manuscript.

\section{References}

Ahlgren G., Lundstedt L., Brett M.T. \& Forsberg C. (1990) Lipid composition and food quality of some freshwater phytoplankton for cladoceran zooplankters. Journal of Plankton Research, 12, 809-818.

Balseiro E.G., Modenutti B.E. \& Queimalinos C.P. (1992) The coexistence of Bosmina and Ceriodaphnia in a south Andes lake - an analysis of demographic responses. Freshwater Biology, 28, 93-101.

Boersma M. \& Vijverberg J. (1994a) The effect of preservation methods on the carbon content of Daphnia. Archiv für Hydrobiologie, 130, 241-247.

Boersma M. \& Vijverberg J. (1994b) Possible toxic effects on Daphnia resulting from the green alga Scenedesmus obliquus. Hydrobiologia, 294, 99-103.

Boersma M. \& Vijverberg J. (1994c) Seasonal variations in the condition of two Daphnia species and their hybrid in a eutrophic lake: evidence for food limitation under field conditions. Journal of Plankton Research, 12, 1793-1809.

Boersma M. \& Vijverberg J. (1995) Synergistic effects of different food species on life history traits of Daphnia galeata. Hydrobiologia, 307, 109-115.

Boersma M., van Tongeren O.F.R. \& Mooij W.M. (1996) Seasonal patterns in the mortality of Daphnia species in a shallow lake. Canadian Journal of Fisheries and aquatic Sciences, 53, in press.

Branstrator D.K. (1994) Profitability of cladoceran prey for Leptodora kindtii. Internationale Vereinigung für Theoretische und Angewandte Limnologie, Verhandlungen, 25, 2413-2417.

Branstrator D.K. \& Lehman J.T. (1991) Invertebrate predation in Lake Michigan - Regulation of Bosmina longirostris by Leptodora kindtii. Limnology $\mathcal{E}$ Oceanography, 36, 483-495.

Browman H.I., Kruse S. \& O’Brien W.J. (1989) Foraging behavior of the predaceous cladoceran, Leptodora kindti, and escape responses of their prey. Journal of Plankton Research, 11, 1075-1088.

Chapman M.A. \& Burns C.W. (1994) Polymorphism and food limitation in 3 Daphnia carinata populations. Internationale Revue der gesamten Hydrobiologie, 79, 477509.

Cowgill U.M., Keating K.I. \& Takahashi I.T. (1985) Fecundity and longevity of Ceriodaphnia dubia/affinis in relation to diet at two different temperatures. Journal of Crustacean Biology, 5, 420-429.

DeMott W.R. (1980) An analysis of the precision of birth and death rate estimates for egg-bearing zooplankters. Evolution and Ecology of Zooplankton Communities (ed. W.C. Kerfoot), pp. 337-345. University Press of New England, Hanover, NH.

DeMott W.R. \& Kerfoot W.C. (1982) Competition among 


\section{M. Boersma and J. Vijverberg}

cladocerans: nature of the interaction between Bosmina and Daphnia. Ecology, 63, 1949-1966.

Duncan A., Lampert W. \& Rocha O. (1985) Carbon weight on length regressions of Daphnia spp. grown at threshold food concentrations. Internationale Vereinigung für Theoretische und Angewandte Limnologie, Verhandlungen, 22, 3109-3115.

Hanazato T. \& Yasuno M. (1984) Growth, reproduction and assimilation of Moina macrocopa fed on Microcystis and/ or Chlorella. Japanese Journal of Ecology, 34, 195-202.

Hart R.C. \& Santer B. (1994) Nutritional suitability of some uni-algal diets for freshwater calanoids - unexpected inadequacies in commonly used edible greens and others. Freshwater Biology, 31, 109-116.

Herzig A. \& Auer B. (1990) The feeding behaviour of Leptodora kindtii and its impact on the zooplankton community of Neusiedler See (Austria). Hydrobiologia, 198, 107-117.

Jamieson C.D. (1980) Observations on the effect of diet and temperature on rate of development of Mesocyclops leuckarti (Claus) (Copepoda, Cyclopoida). Crustaceana, 38, 145-154.

Lampert W. (1977) Studies on the carbon balance of Daphnia pulex de Geer as related to environmental conditions. II. The dependence of carbon assimilation on animal size, temperature, food concentration and diet species. Archiv für Hydrobiologie/Supplement, 48, 310-335.

Lampert W., Rothhaupt K.O. \& von Elert E. (1994) Chemical induction of colony formation in a green alga (Scenedesmus acutus) by grazers (Daphnia). Limnology $\mathcal{E}$ Oceanography, 39, 1543-1550.

Lane P.A. (1978) Role of invertebrate predation in structuring zooplankton communities. Internationale Vereinigung für Theoretische und Angewandte Limnologie, Verhandlungen, 20, 480-485.

Lewis M.A. \& Maki A.W. (1981) Effects of water hardness and diet on productivity of Daphnia magna Straus in laboratory culture. Hydrobiologia, 85, 175-179.

Lundstedt L. \& Brett M.T. (1991) Differential growth rates of 3 cladoceran species in response to mono-algal and mixed-algal cultures. Limnology $\mathcal{E}$ Oceanography, 36, 159-165.

Lunte C.C. \& Luecke C. (1990) Trophic interactions of Leptodora in Lake Mendota. Limnology \& Oceanography, 35, 1091-1100.

Lynch M. (1992) The life history consequences of resource depression in Ceriodaphnia quadrangula and Daphnia ambigua. Ecology, 73, 1620-1629.

Manca M., Spagnuolo T. \& Comoli P. (1994) Variations in carbon and nitrogen content with body length of Daphnia hyalina-galeata sl from laboratory and field observations. Journal of Plankton Research, 16, 1303-1314.
Meyer J.S., Ingersoll C.G., McDonald L.L. \& Boyce M.S. (1986) Estimating uncertainty in population growth rates: Jacknife vs. Bootstrap techniques. Ecology, 67, 1156-1166.

Mordukhai-Boltovskaia E.D. (1958) Preliminary notes on the feeding of the carnivorous cladocerans Leptodora kindtii. Proceedings of the Academy of Sciences of the USSR, Biological Sciences Section, 122, 828-830.

Müller-Navarra D. (1993) Quantifizierung von Nahrungsqualität für herbivores Zooplankton. PhD thesis, University of Kiel, 137 pp.

Paloheimo J.E. (1974) Calculation of instantaneous birth rate. Limnology \& Oceanography, 19, 692-694.

Pennings S.C., Nadeau M.T. \& Paul V.J. (1993) Selectivity and growth of the generalist herbivore Dolabella auricularia feeding upon complementary resources. Ecology, 74, 879-890.

Polishchuk L.V. (1994) Cladoceran birth rate dynamics: does population characteristic of analysis reflect environmental control? Internationale Vereinigung für Theoretische und Angewandte Limnologie, Verhandlungen, 25, 2369-2371.

Polishchuk, L.V. (1995) Direct positive effect of invertebrate predators on birth rate in Daphnia studied with a new method of birth rate analysis. Limnology E Oceanography, 40, 483-489.

Roman M.R. (1984) Utilization of detritus by the copepod, Acartia tonsa. Limnology \& Oceanography, 29, 949-959.

Sterner R.W., Hagemeier D.D. \& Smith W.L. (1993) Phytoplankton nutrient limitation and food quality for Daphnia. Limnology \& Oceanography, 38, 857-871.

Taub F.B. \& Dollar A.M. (1968) The nutritional inadequacy of Chlorella and Chlamydomonas as food for Daphnia pulex. Limnology \& Oceanography, 13, 607-617.

Tessier A.J. (1986) Comparative population regulation of two planktonic Cladocera (Holopedium gibberum and Daphnia catawba). Ecology, 67, 285-302.

Tilman D. (1982) Resource competition and community structure. Princeton University Press, Princeton, 296 pp.

van Donk E. \& Hessen D.O. (1993) Grazing resistance in nutrient-stressed phytoplankton. Oecologia, 93, 508-511.

Vanni M.J. \& Lampert W. (1992) Food quality effects on life history traits and fitness in the generalist herbivore Daphnia. Oecologia, 92, 48-57.

Vijverberg J. (1976) The effect of food quantity and quality on the growth, birth-rate and longevity of Daphnia hyalina Leydig. Hydrobiologia, 51, 99-108.

Vijverberg J. (1989) Culture techniques for studies on the growth, development and reproduction of copepods and cladocerans under laboratory and in situ conditions: a review. Freshwater Biology, 21, 317-373.

(Manuscript accepted 17 August 1995) 